\title{
Early failure of a non-cemented femoral stem after minimal-invasive total hip arthroplasty: cause analysis and classification
}

\author{
Jan P. Benthien $\cdot$ Wolf Siepen
}

Received: 23 December 2011/Accepted: 14 April 2012/Published online: 6 May 2012

(C) Springer-Verlag 2012

\begin{abstract}
In this paper, we present a 77-year-old female patient with an early failure of a non-cemented femoral stem 6 months after implantation. We evaluate possible reasons for the implant failure in our case against the literature. Risk factors for stem failure include a BMI $>30$, varus implantation, a high femoral canal cortex ratio, and a small implant. It should be distinguished between modular and non-modular stems as well as cemented and noncemented. Early failure would be $<1$ year postoperatively, late failure $>1$ year postoperatively. A classification of stem failure differentiating time and cause is suggested as this seems to be missing in the literature.
\end{abstract}

Keywords Femoral stem - Fatigue fracture .

Total hip prosthesis $\cdot$ Non-cemented

\section{Introduction}

Failures of any component of a prosthesis are compromising for the patient and the patient's confidence in orthopaedic hardware and quality. Inevitably, revision operations have to be performed, which put the patient at an additional risk. Although the risk of implant failure seems to be lower today due to modern implant designs and materials as well as modern operative techniques, implant failures do occur.

\section{J. P. Benthien $(\square)$}

Department of Trauma Surgery, University of Basel,

Spitalstr. 21, 4031 Basel, Switzerland

e-mail: jbenthien@uhbs.ch

W. Siepen

Department of Orthopaedics,

Cantonal Hopital Bruderholz, Basel, Switzerland
Implant failure of a hip prosthesis may be divided into failure of its components:

Cemented and non-cemented acetabular cups may fracture and dislocate $[1,2]$, while fractures or dislocations of either polyethylene or ceramic liners may occur due to excessive loading $[1,2]$. Even the recently introduced highlinked polyethylene liners may crack [3].

Stem fractures are mostly divided into early and late failures. However, a clear definition of the appropriate time limit to distinguish between these two has yet to be found.

Stem fractures may be further divided into fractures of a cemented or a non-cemented shaft. Fractures of cemented stems mostly seem to occur secondary after loosening or imprecise cementing techniques $[1,2,4]$. They may be further divided into fractures of modular and primary prostheses [5-7]. Very rarely, multiple stem fractures are described [8].

The most common reason for stem fracture seems to be due to wrong implant sizing or malpositioning in relation to the geometry of the femur $[1,2,9,10]$. The reported stem failures in these cases were almost all located in the middle to distal third of the stem, where the highest tensile stress values were calculated after loss of the proximal support [11]. When the stem is positioned in varus, higher tensile forces could be calculated than in neutral or valgus alignment [11].

Another factor may be the patient's weight and height. Obesity is described in the literature as a possible risk factor [4, 5, 12-14].

Some failures were clearly due to material inhomogeneities caused by casting defects, but this seems to have been in the earlier cases [7]. However, Della Valle et al. [15] describe late fatigue fractures on a modern cobalt chrome alloy stem. 


\section{Case report}

A 77-year-old otherwise healthy active female with a BMI $>30$ had a minimal-invasive total hip arthroplasty 6 months prior to obtaining a fracture of her femoral stem. The procedure was performed via an anterolateral approach. The implanted stem was a Corail (C) cementless stem (DePuy Johnson and Johnson, Warsaw, USA). The early postoperative course and the rehabilitation period were uneventful, and the patient was very satisfied despite a slightly displaced fracture of the trochantor major in the postoperative 6-week control.

After 6 months, the patient experienced femoral shaft pain after heavy lifting and a minor trauma. The radiographs showed a fracture of the femoral stem in the distal third (Fig. 1), and the patient was referred to our hospital.

The patient was unable to put weight on her leg but she could walk for ca. $10 \mathrm{~min}$. She presented with disabling ventral femoral pain and groin pain. She could not walk pain free. Intra-operatively, we found a firmly bony

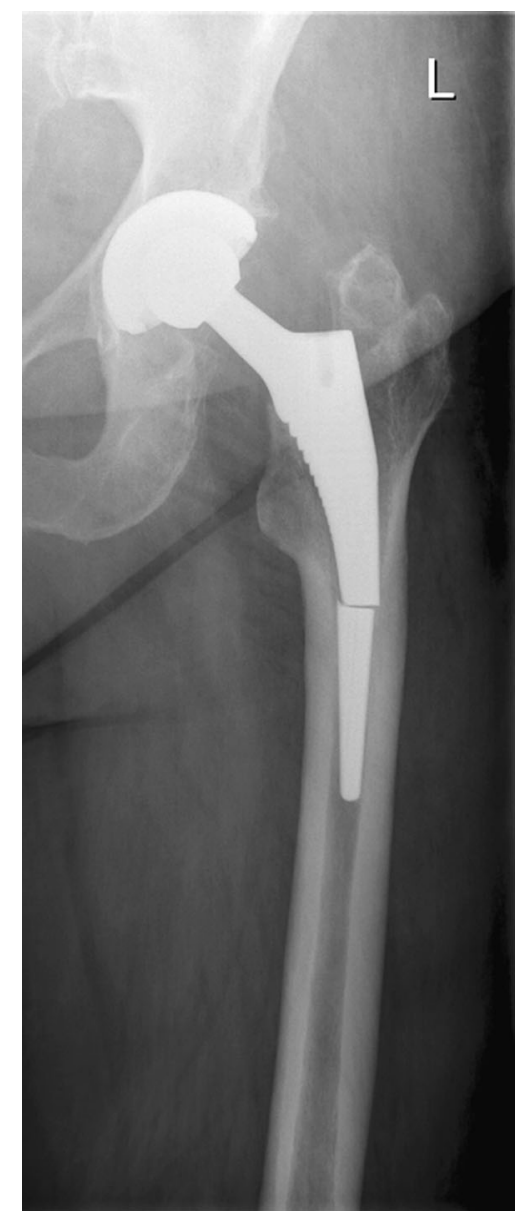

Fig. 1 a.p. hip view after fracture of the stem. Note the slightly varus position, the fracture of the trochanteric tip, the Dorr A femoral configuration and the wide proximal form as compared to a narrow distal femoral space (champagne flute form) integrated distal stem and a non-integrated proximal part of the stem with fibrous tissue coating (Fig. 2). The proximal stem fragment could be pulled out. A transfemoral approach was performed to remove the distal third of the stem, and a revision femoral stem was implanted.

The fractured tip of the greater trochanter could not be attached because it was fractured in small parts. The bulk of the pelvi-trochanteric muscles remained attached to the remaining greater trochanter. The hip was stable against dislocation. Partial weight bearing was allowed, and the patient was referred to the out-patient rehabilitation programme. The 6-week control showed a pain-free patient able to walk on two crutches. After 3 months, the patient could walk pain free without support. She was able to put full weight on the affected side. Internal-external rotation and ab-/adduction were limited. There was no insufficiency of the pelvi-trochanteric musculature noted.

\section{Material analysis by the manufacturer}

The Centre Régional d'Innovation et de Transfer de Technologie (CRITT) in Charleville Meziers, France, performed a binocular microscopic examination and scanning electron microscopy (SEM). The following conclusions were drawn:

The stem was stressed in a monotonous way without a single or peak overload. The fracture initiated at the most lateral groove of the stem under progressive fissuring

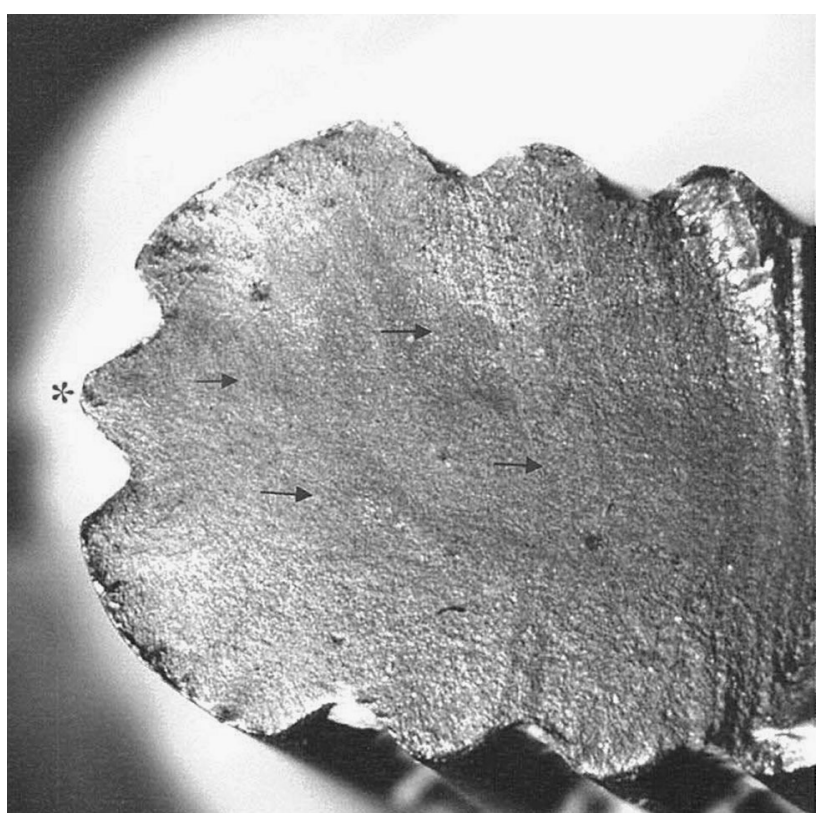

Fig. 2 Cross-section of the fracture site. The most lateral groove (asterisk) is the initiation point for the lines that indicate fatigue stress (arrows) from lateral to medial. Magnification $\times 10$. Photograph with kind permission by DePuy Johnson and Johnson, Switzerland 


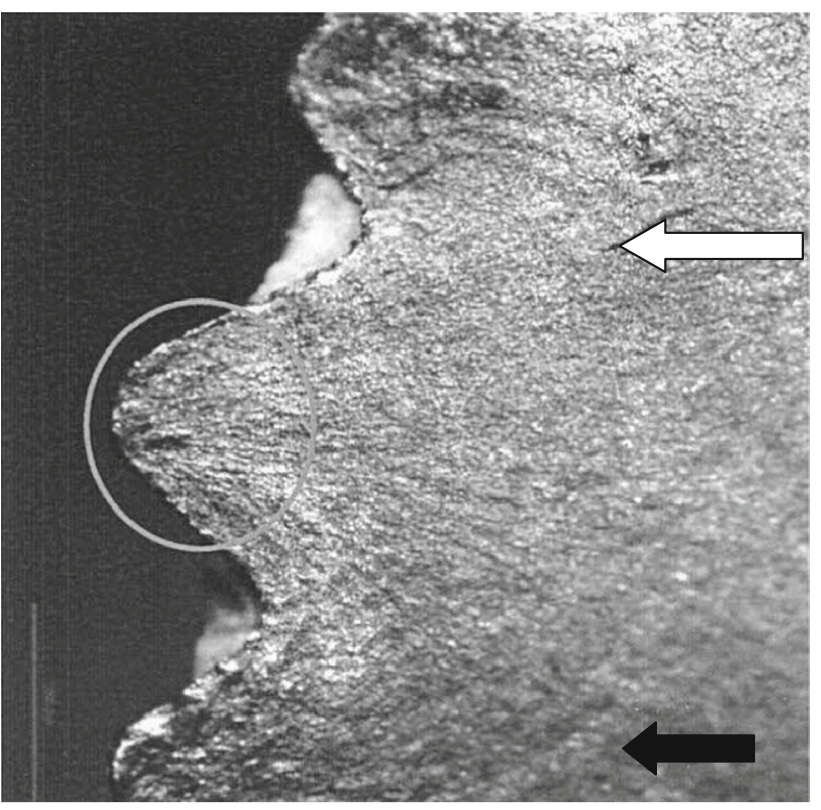

Fig. 3 Lines (black arrow) radiate semi circularly from the lateral groove (circle). A crack radiating from the lines may be noted (white arrow) indicating fatigue fracture. The lateral groove received the peak stress. Magnification $\times 20$. Photograph with kind permission from DePuy Johnson and Johnson, Switzerland

(Figs. 2, 3). The hardness test was appropriate so a fracture due to failed raw material could be excluded.

\section{Discussion}

The early literature concerning prosthesis failure point to material defects and possible default cement technique. Collis and Galante $[12,13]$ refer to inferior quality of the implanted material leading to fatigue fractures. However, it is not always distinguished between cement and prosthesis fracture. Wroblewski [14] describes a series of 120 cases without differentiating between stem and cement failure. We think that a differentiation between a stem failure and failure of its cemented fixation should be made. Our suggested classification (Table 1) includes stem fractures in cemented hips, not fractures of the cement.

With new implant materials as cobalt-steel alloys material properties seems to have improved compared to simple steel implants, and such fatigue fractures are now less often observed [4, 15]. Almost all studies point to obesity as a risk factor.

The positioning and the alignment of the implant to the femoral axis are also quite important. Andriacchi et al. [11] concluded in a stress analysis of the femoral stem that loss of proximal support puts increased stress on the distal part leading to fatigue failure. This study also stresses the role of increased body weight.

According to these findings, we suggest that a femoral configuration Dorr A [16] with a thick cortical bone in combination with a high canal-calcar ratio (CC-ratio), a champagne flute form, would predispose to a varus implantation leading to maximal lateral stress in the distal third of the stem [11]. As the wide proximal femur would not support the stem, much stress would be on the distal half [11]. We have therefore put the Dorr A-type femur as a risk factor in our classification (Table 1). Kishida et al. [4] reach a similar conclusion and define the champagne flute form as a risk factor.

According to the manufacturer, more than 700,000 stems of this system were implanted since 1986. Since 2002 , ca. 100 stem fractures were reported from the manufacturer's complaint department. In our case, the fracture was distal and exactly in the region where osseous integration to the femur was observed intra-operatively, whereas the further proximal parts showed no integration and fibrous tissue ingrowths. The implanted stem also showed a slight varus positioning in the a.p view. The implant design and size $[4,10,11]$ were also identified as a risk factor for fractures when inserted into a champagneflute-shaped femur with no direct medial support in the calcar region. This relation of implant design to femoral shaft configuration may lead to an unfavourable varus alignment. This may mislead the surgeon to rather choose a smaller implant than to correct the alignment with a bigger implant.

A wide femoral entrance with narrowing of the dia- and metaphysis (a champagne flute design) seems to predispose varus alignment of the implant [12]. In this position, repetitive excess bending and twisting may produce fatigue fractures initiating in the lateral parts of the prosthesis (Figs. 2, 3). Therefore, it is important to rule out varus positioning or an undersized implant intra-operatively. The use of fluoroscopy is advised.
Table 1 Classification of stem failure

\begin{tabular}{|c|c|c|}
\hline $\begin{array}{l}\text { Time of failure } \\
\text { postoperatively }\end{array}$ & $\begin{array}{l}\text { Early: }<1 \text { year } \\
\text { postoperatively }\end{array}$ & $\begin{array}{l}\text { Late: }>1 \text { year } \\
\text { postoperatively }\end{array}$ \\
\hline Fixation of stem & Cemented & Non-cemented \\
\hline Type of prosthesis & Non-modular & Modular \\
\hline Site of stem failure & Proximal $50 \%$ & Distal $50 \%$ \\
\hline Risk factors & $\begin{array}{l}\text { BMI }>30 \text {, varus alignment, } \\
\text { Dorr A femoral shaft } \\
\text { configuration, high canal to } \\
\text { calcar ratio, small stem }\end{array}$ & \\
\hline
\end{tabular}


In champagne-flute-shaped femurs, the Dorr Type A configuration [16] demonstrating a high CC-ratio and a thick cortical bone with a small intra-medullary space, special caution should be exercised to avoid varus malalignment and a small implant $[4,11]$. If any doubts arise, intra-operative fluoroscopy should be performed to ascertain correct stem positioning.

In modular stems, the same principles may be applied $[5,9,15]$. This should raise the question whether a revision system that is designed for distal fixation should have its weakest point (the hinge between the proximal and distal parts) at the place where most tensile forces occur.

Short-stemmed prostheses seem to be at risk, too, if the loose their proximal support and drift further into varus position [10]. As these should be implanted in a varus position, there are several risk factors that should be taken into account when choosing this type of implant.

In our case, the following risk factors for an early non-cemented primary stem failure could be identified: a relatively small implant inserted in varus alignment, a champagne-flute-shaped proximal wide femur with a narrow diaphysis and a thick cortical thickness (Dorr A configuration) and a BMI $>30$. According to the manufacturer's material analysis, a material defect could be excluded, and the fracture could be attributed to fatigue failure.

To what extent the intra-operative fracture of the trochanter major may have contributed to the stem fracture is uncertain, and incidence is not described in literature. It may have contributed to the loss of proximal femoral support.

\section{Conclusion}

We suggest a classification of femoral stem fractures: cemented or non-cemented, modular versus non-modular, early $(<1$ year postoperatively), late $(>1$ year postoperatively). The following risk factors were identified: varus alignment, small stem, femoral shaft configuration Dorr A in combination with a champagne flute form, BMI $>30$ (Table 1), high CC-ratio.

Material defects seem to have become rare.

The reporting and classification of fractured stems is important because the number of implanted total hip prostheses is increasing as is the number of new stem designs and implantation techniques. Documentation in a prosthesis register is recommended.

Conflict of interest There is no conflict of interest for the paper.

\section{References}

1. Lee YK, Ha YC, Yoo JJ et al (2010) Alumina-on-alumina total hip arthroplasty: a concise follow-up, at a minimum of ten years, of a previous report. J Bone Joint Surg Am 92(8):1715-1719

2. Salih S, Currall VA, Ward AJ et al (2009) Survival of ceramic bearings in total hip replacement after high-energy trauma and periprosthetic acetabular fracture. J Bone Joint Surg Br 91(11): $1533-1535$

3. Furmanski J, Kraay MJ, Rimnack CM (2010) Crack initiation in retrieved cross-linked highly cross-linked ultrahigh-molecularweight polyethylene acetabular liners. An investigation of 9 cases. J Arthroplast. doi:10.1016/j.arthr.2010.07.016

4. Kishida Y, Sugano N, Ohozono K et al (2002) Stem fracture of the cementless spongy metal Lübeck hip prosthesis. J Arthroplast 17(8):1021-1027

5. Lakstein D, Eliaz N, Ofer L et al (2011) Fracture of cementless femoral stems at mid term junction in modular revision hip arthroplasty systems. J Bone Joint Surg Am 93:57-65. doi:10. 2106/JBJS.I.01589

6. Busch CA, Charles MN, Haydon CM et al (2005) Fractures of distally-fixed femoral stems after revision arthroplasty. J Bone Joint Surg Br 87(10):1333-1336

7. Dall DM, Learmonth ID, Solomon MI et al (1993) Fracture and loosening of Charnley femoral stems. J Bone Joint Surg $\mathrm{Br}$ 75-B:259-306

8. Jarvi K, Kerry RM (2007) Segmental stem fracture of a cemented femoral prosthesis. J Arthroplast 22(4):612-616

9. Efe, T, Schmitt J (2011) Case report analyses of prosthesis stem failures in noncemented modular hip revision prostheses. J Arthroplast 26(4):665.e7-665.e12

10. Ishague BA, Stürz H, Basad E (2011) Fatigue fracture of a short stem hip replacement: a failure analysis with electron microscopy and review of the literature. J Arthroplast. doi:10.1016/j.arthr.2010.05.21

11. Andriacchi TP, Galante JO, Belytschko TB et al (1976) A stress analysis of the femoral stem in total hip prosthesis. J Bone Joint Surg 58-A:618-624

12. Collis DK (1977) Femoral stem fracture in total hip replacement. J Bone Joint Surg 59-A:1033-1041

13. Galante JO, Rostocker W, Doyle JM (1975) Failed femoral stems in total hip prosthesis. J Bone Joint Surg 57-A:230-236

14. Wroblewski BM (1982) Fractured stem in total hip replacement. Acta Orthop Scand 53:279-284

15. Della Valle AG, Becksac B, Anderson J (2005) Late fatigue fracture of a modern cemented forged cobalt chrome stem for total hip arthroplasty. J Arthroplast 20(8):1

16. Dorr LD, Faugere MC, Mackel AM et al (1993) Structural and cellular assessment of bone quality of proximal femur. Bone 3:231-242 